\title{
The prevalence of prolonged jaundice due to breast milk jaundice in hospitalized newborn; a study among Iranian neonates
}

\author{
Fatemeh Eghbalian $^{10}$, Roya Raeisi ${ }^{1 *}$, Shadi Eslah', Nasrin Jiryaee ${ }^{2}$ \\ ${ }^{1}$ Hearing Disorders Research Center, Beasat Hospital, Hamadan University of Medical Sciences, Hamadan, Iran \\ ${ }^{2}$ Department of Social Medicine, School of Medicine, Hamadan University of Medical Sciences, Hamadan, Iran
}

\section{*Correspondence to Roya Raeisi, \\ Email; r.raisi@umsha.ac.ir, r_reisi2@yahoo.com}

Received 10 Aug. 2020 Accepted 1 Dec. 2020 Published online 13 Dec. 2020

Keywords: Prolonged jaundice, Breast milk jaundice, Prevalence

\begin{abstract}
Introduction: Breast milk jaundice is considered as the most common cause for neonatal jaundice; however, its epidemiological aspects in some population remain unclear.

Objectives: The present study aimed to assess the prevalence of breast milk jaundice and its main determinant among a group of neonates in western Iran.

Patients and Methods: This cross-sectional study was conducted on 413 neonates hospitalized due to prolonged jaundice in Besat hospital in Hamadan, Iran. The study information was collected by reviewing the hospital's recorded files.

Results: In total, 413 neonates hospitalized were assessed in this study. The main reason for appearing jaundice included; $72.4 \%$ of cases of jaundice were due to breast milk, urinary tract infection in $4.2 \%$ of cases, glucose6-phosphate dehydrogenase deficiency (G6PD) in 5.8\% of cases, hypothyroidism in 1.2\% of cases. Out of 299 neonates suffering from breast milk jaundice, $126(42.1 \%)$ were male, and $173(57.9 \%)$ were female with the overall average age of $16.68 \pm 2.14$ days. Jaundice appeared at less than two days of age in $29.4 \%$ of neonates, between 15 to 20 days of age in $64.9 \%$, and more than 20 days of age in $5.7 \%$ of cases.

Conclusion: Breast milk jaundice is considered as the most common reason for neonatal jaundice in our population, which affects more than two-thirds of our neonates. Additionally, the peak age of this phenomenon is between 15 and 20 days. The appearing breast milk jaundice is independent of gender, age, and birth weight or baseline total serum bilirubin level.
\end{abstract}

Citation: Eghbalian F, Raeisi R, Eslah S, Jiryaee $\mathrm{N}$. The prevalence of prolonged jaundice due to breast milk jaundice in hospitalized newborn a study among Iranian neonates. Immunopathol Persa. 2021;7(2):e22. DOI: 10.34172 ipp.2021.22.

\section{Introduction}

Jaundice is the most common cause of infant hospitalization in the first month of birth. More than half of mature infants and fourthfifths of premature babies develop some forms of jaundice by passing 2 to 5 days from birth (1-4). Under normal conditions, the level of indirect bilirubin in umbilical cord blood is ranged from 1 to $3 \mathrm{mg} / \mathrm{dL}$ that rapidly increases at a rate of less than $5 \mathrm{mg}$ / $\mathrm{dL}$ in 24 hours (1-5). Thus, jaundice appears at the second and third days after birth, and bilirubin levels slightly increase at the third and fourth days, and then decrease to the levels under $2 \mathrm{mg} / \mathrm{dL}$ on days 5 to 7 of birth (3-5). Accordingly, jaundice associated with these changes is called physiological jaundice due to the breakdown of neonatal red blood cells with transient limitation of bilirubin conjugation by the premature neonatal liver (1,6-10). Physiological jaundice is mainly

\author{
Key point \\ Breast milk jaundice is considered as the most \\ common cause for neonatal jaundice.
}

diagnosed by rejecting the known causes of jaundice based on history, clinical findings, and laboratory data (1-10). One of the risk factors for indirect hyperbilirubinemia is the lack of breastfeeding that occurs from the second to fourth days of life $(1,3,4,8,10)$. This type of jaundice is an exacerbated type of physiological jaundice, with bilirubin levels increasing to about 15 to $17 \mathrm{mg} / \mathrm{dL}$ (1). Dehydration and calorie deficiency in infants are among the contributing factors to this type of jaundice, therefore proper and intermittent breastfeeding, for more than ten times in 24 hours, co-sleeping with mother and nocturnal breastfeeding are effective factors on preventing this type of jaundice

\footnotetext{
Copyright ( $\odot 2021$ The Author(s); Published by Nickan Research Institute. This is an open-access article distributed under the terms of the Creative Commons Attribution License (http://creativecommons.org/licenses/by/4.0), which permits unrestricted use, distribution, and reproduction in any medium, provided the original work is properly cited.
} 
(5-10). Overall, the occurrence of icter in the first 24 to 36 hours after birth could increase bilirubin to more than $5 \mathrm{mg} / \mathrm{dL}$ in 24 hours. Additionally, it could increase total bilirubin to over $12 \mathrm{mg} / \mathrm{dL}$ in the term newborn and more than 10 to $14 \mathrm{mg} / \mathrm{dL}$ in the preterm newborn, since a direct bilirubin concentration of more than $2 \mathrm{mg} /$ $\mathrm{dL}$ and continuing jaundice for 14 to 21 days after birth is considered to be pathologic $(5,9)$.

The prolonged jaundice is also defined as a type of jaundice lasting for more than 14 days in term infants and more than 21 days in premature infants $(2,4,5)$. The most important causes of prolonged jaundice are breastfeedingrelated jaundice, glucose-6-phosphate dehydrogenase (G6PD) deficiency, urinary tract infection, and hypothyroidism (10). About $10 \%$ to $30 \%$ of breastfeeding; infants have prolonged jaundice (2). In neonates hospitalized with prolonged jaundice, all the relevant tests including urine analysis and culture, complete blood count, Coombs test, G6PD deficiency, plasma hemoglobin and hematocrit, urine resuscitation tests, thyroid tests, and family history of prolonged jaundice should be examined $(3,5,6)$. By excluding such etiologies, breast milk jaundice can be suggested. The increased level of unconjugated bilirubin up to $20-25 \mathrm{mg} / \mathrm{dL}$ is the highest level of bilirubin found in breast milk jaundice, which is very rare occurred in less than $1 \%$ of infants. In two-thirds of infants, the level of bilirubin may reach $10 \mathrm{mg} / \mathrm{dL}$, and in one-third of them, to less than $6 \mathrm{mg} / \mathrm{dL}(6-8,11)$. If the level of bilirubin exceeds the permissible limit, it may lead to irreversible consequences in the baby, such as brain complications and hearing disorders $(12,13)$. In addition, in recent years, some cases of infants with severe hyperbilirubinemia related to breast milk jaundice have been reported even in healthy infants without evidence of systemic or infectious diseases, which indicate an increasing trend $(14,15)$.

\section{Objectives}

The present study aimed to assess the prevalence of breast milk jaundice and its main determinant among a group of Iranian infants.

\section{Patients and Methods \\ Study design}

This cross-sectional study was performed on 413 consecutive neonates hospitalized in Besat hospital due to prolonged jaundice in Hamadan, Iran (April 2011 to 2016). The samples were collected using the simple and non-probable and straightforward method. The study information was collected by reviewing the hospital's recorded files; and therefore, those files with incomplete data were not included in the study. The collected data was recorded in the checklist designed by the questionnaire consisting baseline characteristics related to a neonatal condition such as gender, age, birth weight, gestational age, the level of total and direct bilirubin, and underlying disorders, which might affect the likelihood of neonatal jaundice [such as urinary tract infection, G6PD deficiency or hypothyroidism], and history of breastfeeding. The study endpoint was at first determining the overall prevalence of breast milk jaundice, and secondly, assessing the main determinants of jaundice among baseline variables of the neonates.

\section{Ethical issues}

The research followed the tenets of the Declaration of Helsinki and its later amendments. The Ethics Committee of Hamadan University of Medical Science approved this study (Ethical code\#ir.umsha.rec.1397.427). This work has been conducted as part of the M.D, thesis by Shadi Eslah at this university.

\section{Statistical analysis}

The mean \pm standard deviation (SD) of quantitative variables was expressed and then classified based on absolute frequencies and percentages for categorical variables. The Kolmogorov-Smirnov test was used for analyzing the normality of data. Chi-square test or Fisher exact test were used to compare the categorical variables. The statistical software SPSS version 16.0 was used (SPSS Inc., Chicago, IL). $P$ values less than or equal to 0.05 were considered statistically significant.

\section{Results}

In total, 413 neonates hospitalized were assessed in this study. The main reason for appearing jaundice included; $72.4 \%$ of cases of jaundice were due to breast milk, urinary tract infection in $4.2 \%$ of cases, G6PD deficiency in $5.8 \%$ of cases, hypothyroidism in $1.2 \%$ of cases (Table 1 ). Out of 299 neonates suffering from breast milk jaundice, 126 (42.1\%) were male, and 173 (57.9\%) were female with the overall average age of $16.68 \pm 2.14$ days (ranged from 14 to 25 days). Jaundice appeared at less than two days of age in $29.4 \%$ of neonates, between 15 to 20 days of age in $64.9 \%$, and more than 20 days of age in $5.7 \%$. Only $6.0 \%$ of neonates were premature at birth by considering a gestational age less than 37 weeks. The mean gestational age in those with prolonged breast milk jaundice was ranged from 33 to 40 weeks (birth age by week). Regarding the status of birth weight in those with breast milk jaundice, the mean birth weight was $3166.22 \pm 368.42 \mathrm{~g}$ ranged from 2000 to $4200 \mathrm{~g}$ that $3.7 \%$ were low birth weight and the others had normal weight at birth. As shown in Table 2, comparing baseline parameters between these two groups who were

Table 1. Main reasons for prolonged jaundice

\begin{tabular}{ll}
\hline Breast milk jaundice & $72.4 \%$ \\
\hline Urinary tract infection & $4.2 \%$ \\
\hline G6PD deficiency & $5.8 \%$ \\
\hline Hypothyroidism & $1.2 \%$ \\
\hline Urinary tract infection and G6PD & $1.0 \%$ \\
\hline Hypothyroidism and G6PD & $0.2 \%$ \\
\hline
\end{tabular}


Table 2. Comparing baseline parameters between the two groups suffering from breast milk jaundice and those with jaundice due to other etiologies

\begin{tabular}{lccc}
\hline Variable & Breast milk & Other causes & $\boldsymbol{P}$ value \\
\hline Female gender & $173(57.9)$ & $60(52.6)$ & 0.338 \\
Age of jaundice onset, day & $16.68 \pm 1.44$ & $17.14 \pm 2.70$ & 0.048 \\
Birth weight, gram & $3166.22 \pm 368.42$ & $3101.18 \pm 374.16$ & 0.211 \\
Gestational age, week & $38.49 \pm 0.97$ & $38.43 \pm 1.06$ & 0.991 \\
Total bilirubin level, mg/dL & $11.46 \pm 1.57$ & $11.40 \pm 1.34$ & 0.975 \\
\hline
\end{tabular}

suffering breast milk jaundice and those with jaundice due to other etiologies, showed no differences in neonates' gender $(P=0.338)$, birth weight $(P=0.211)$, gestational age $(P=0.991)$, and baseline total bilirubin levels $(P=0.975)$ between the two groups. However, the mean age of jaundice onset was significantly lower in those neonates with breast milk jaundice as compared to the other group $(16.68 \pm 1.44$ days versus $17.14 \pm 2.70$ days; $P=0.048)$.

\section{Discussion}

The exact etiology of breast milk jaundice has not been determined yet. Most of the proposed etiologies involve the factors present in the human breast milk itself. Another area of investigation has been the potential genetic mutations that are present in the affected newborns. From the epidemiological aspects, the prevalence rate of breast milk jaundice in developed countries is estimated to be from $20 \%$ to $30 \%$ for newborns from 3 to 4 weeks of age whose feeding is predominantly via breastfeeding. About $30 \%-40 \%$ of breastfed infants are expected to have bilirubin levels greater than or equal to $5 \mathrm{mg} / \mathrm{dL}$ with approximately $2 \%-4 \%$ of exclusively breastfed infants having bilirubin levels over $10 \mathrm{mg} / \mathrm{dL}$ in third week of life (16). Investigating some middle-income studies also showed the frequency of $20 \%-28 \%$ for breast milk jaundice presented at four weeks of age with the mean total serum bilirubin level of higher than $5 \mathrm{mg} / \mathrm{dL}$ (17). In our study, we did not assess the overall prevalence of breast milk jaundice in our population; however, we could show that this type of jaundice involved a large part of the causes of prolonged jaundice. In this regard, about $72.4 \%$ of all neonates with prolonged jaundice suffered from the subtype of breast milk jaundice; and therefore, this type of jaundice is identified as the most common type among our neonates aged between 14 and 25 days. Although in our study, the most common cause of jaundice was related to inadequate breastfeeding or breast milk jaundice, it should not be generalized to all populations. In a similar study on the same population by Agrawal et al (18), most common cause of persistent jaundice in both term and preterm babies was breast milk jaundice (66\%), other causes include cephalohematoma (7\%), isoimmunization (7\%), sepsis (4\%) ABO incompatibility (3\%).and (10\%) hypothyroidism which was approximately inconsistent with our survey. In another study by Weng in Taiwan (19), the prolonged jaundice was more common in neonates of fed breast milk than those who were given formula. The main causes for prolonged jaundice may be variant emphasizing on the effect of genetics and ethnicity along with the known pathological conditions for occurring prolonged jaundice. Weng et al in a study in Taiwan, identified the common genetic variant of neonates with icter (20). When the baby receives inadequate milk, breast milk jaundice is raised, which is not relevant to jaundice of breast milk. A baby's bowel movements increase when he/she eats sufficient amounts of breast milk, hence it improves the secretion of the buildup of bilirubin.

If a newborn does not start a well breastfed, breast milk jaundice is raised, which has an improper lactation, thereby other substitutes related to breastfeeding should be taken. Often breast milk jaundice is relieved by increasing breastfeeding.

Advice for better breastfeeding is necessary to make sure that the baby is getting enough. Thus, it should be minutely paid attention that, the differentiating breastfeeding jaundice and breast milk jaundice to identifying the epidemiological aspects, the main risk factors, and more important treatment approaches are essential.

\section{Conclusion}

In total, based on the results of the present study, we can suggest breast milk jaundice caused by breastfeeding by ruling out other causes of jaundice such as urinary tract infection, G6PD, and hypothyroidism by simple testing. Early diagnosis and treatment of these disorders could effectively prevent further complications in infants.

Other reasons are also considered as the less common causes of prolonged jaundice, which suggest having a proper family history of suspected Crigler-Najjar syndrome, metabolic diseases, and also applying other specific diagnostic tests to rule out all causes of prolonged jaundice.

Since it is the most common cause of prolonged jaundice with the diagnosis of prolonged jaundice caused by breast milk, we recommend performing initial evaluation to rule out other causes and continue breastfeeding.

\section{Limitation of the study}

The study was single-center and conducted on a relatively low-sample size.

\section{Authors' contribution}

FE and SE were the principal investigators of the study. SE and NJ were included in preparing the concept and design. RR revisited the manuscript and critically evaluated the intellectual contents. All authors participated in preparing the final draft of the manuscript, revised the manuscript and critically evaluated the intellectual contents. All authors have read and approved the content of the manuscript and confirmed the accuracy or integrity of all part of the work.

\section{Conflicts of interest}

The authors declare that they have no competing interests. 
Ethical considerations

Ethical issues (including plagiarism, data fabrication, double publication) have been completely observed by the authors.

\section{Funding/Support}

None.

\section{References}

1. Chee YY, Chung PH, Wong RM, Wong KK. Jaundice in infants and children: causes, diagnosis, and management. Hong Kong Med J. 2018;24(3):285-292. doi:10.12809/hkmj187245

2. Bratton S, Cantu RM, Stern M. Breast Milk Jaundice. In: StatPearls. Treasure Island (FL): StatPearls Publishing; 2020.

3. Eghbalian F, Pourhossein A, Zandevakili H. Effect of clofibrate in non-hemolytic indirect hyperbiliru-binemia in full term neonates. Indian J Pediatr. 2007;74:1003-1006. doi:10.1007/ s12098-007-0184-x

4. Maisels MJ, Bhutani VK, Bogen D, Newman TB, Stark AR, Watchko JF. Hyperbilirubinemia in the newborn infant $\geq 35$ weeks' gestation: an update with clarifications. Pediatrics. 2009;124(4):1193-8 . Doi: 10.1542/peds.2009-0329

5. Agrawal V, Goyal AK, Sharma JN, Yadav MD. Different causes of prolonged unconjugated Jaundice in the newborns. International Journal of Contemporary Pediatrics. 2017;4(3):984

6. Misels MG. Prevention and management of neonatal hypebilirubinemia. In: MacDonald MG, Mullett MD, Seshia MM, eds. Avery's Neonatology Pathophysiology \& Management of newborn. 6th ed. Philadelphia, PA: Williams \& Wilkins; 2005. p. 825-33.

7. Porter ML, Dennis BL. Hyperbilirubinemia in the term newborn. Am Fam Physician. 2002;65:599-606.

8. Preer GL, Philipp BL. Understanding and managing breast milk jaundice. Arch Dis Child Fetal Neonatal Ed. 2011;96:F461-6. doi:10.1136/adc.2010.184416.

9. Gundur NM, Kumar P, SundaramV, Thapa BR, Narang A. Natural history and predictive risk factors of prolonged unconjugated jaundice in the newborn. Pediatr Int. 2010;52:769-72. doi:
10.1111/j.1442-200X.2010.03170.x.

10. Eghbalian F, Rafienezhad H, Farmal J. The lowering of bilirubin levels in patients with neonatal jaundice using massage therapy: A randomized, double-blind clinical trial. Infant Behav Dev. 2017;49:31-36. doi:10.1016/j.infbeh.2017.05.002

11. Stoll B, Adams-Chapman I, Kliegman R, Behrman R, Jenson H, Stanton B. Nelson Textbook of Pediatrics. Elsevier; 2020.

12. Hertz GS. Supplemental breast milk is the best milk. Arch Pediatr Adolesc Med. 1999;153:655.

13. Lee K-S, Perlman M, Ballantyne M, Elliott I, To T. Association between duration of neonatal hospital stay and readmission rate. J Pediatr. 1995;127(5):758-66. doi: 10.1016/S00223476(95)70170-2.

14. Basu K, Das PK, Bhattacharya R, Bhowmik PK. A new look on neonatal jaundice. J Indian Med Assoc. 2002;100:556-60.

15. Carbonell X, Botet F, Figueras J, Riu-Godó A. Prediction of hyperbilirubinaemia in the healthy term newborn. Acta Paediatrica. 2001;90:166-70. doi: 10.1080/080352501300049343.

16. Ullah S, Rahman K, Hedayati M. Hyperbilirubinemia in neonates: types, causes, clinical examinations, preventive measures and treatments: a narrative review article. Iran J Public Health. 2016;45:558-68.

17. Maruo Y, Morioka Y, Fujito H, Nakahara S, Yanagi T, Matsui $\mathrm{K}$, et al. Bilirubin uridine diphosphate-glucuronosyltransferase variation is a genetic basis of breast milk jaundice. J. Pediatr. 2014;165:36-41. doi: 10.1016/j.jpeds.2014.01.060.

18. Agrawal V, Goyal AK, Sharma JN, Yadav MD. Different causes of prolonged unconjugated Jaundice in the newborns. IJCP. 2017;4(3):984. doi:10.18203/2349-3291.ijcp20171712.

19. Cheng SW, Chiu YW, Weng YH. Etiological analyses of marked neonatal hyperbilirubinemia in a single institution in Taiwan. Chang Gung Med J. 2012;35:148-54. doi:10.4103/2319-4170.10615.

20. Weng YH, Chiu YW, Cheng SW, Yang CY. Risk assessment of gene variants for neonatal hyperbilirubinemia in Taiwan. BMC Pediatr. 2016;16:144. doi:10.1186/s12887-016-0685-8. 